\title{
SABERES DOCENTES RELATIVOS À PRÁTICA DE CALCULAR NO PROCESSO DE FORMAÇÃO CONTINUADA DE PROFISSIONAIS QUE ATUAM NO ENSINO FUNDAMENTAL
}

\author{
Arlindo José de Souza Junior ${ }^{1}$ \\ Grazielle Eloísa Balduino \\ Myrtes Dias da Cunha ${ }^{3}$
}

\begin{abstract}
RESUMO: O presente trabalho discute aspectos de um curso de formação continuada de professores do Ensino Fundamental, denominado "Mídias nas Aulas de Matemática". A cultura do cálculo é milenar, tendo início a partir do momento em que o homem começa a se relacionar uns com outros e a juntar objetos, há milhões de anos atrás. Neste trabalho, buscamos apresentar o curso de formação continuada e como surgiu o tema "cultura do cálculo"; procuramos conhecer os significados e sentidos do cálculo desde a sua origem até os tempos atuais; tentamos entender os diferentes instrumentos de calcular, que permitem ao aluno aprender as operações básicas da Matemática e mostrar potencialidades de saberes que compõem uma cultura do cálculo produzida coletivamente por professores da rede municipal, de escolas particulares, pesquisadores e estudantes da licenciatura. Durante a realização desse curso, compreendemos que não basta ser a favor ou contra o uso da calculadora ou outras técnicas de cálculo, é preciso compreender o que são tais instrumentos, desmistificando-os e, a partir daí, definir caminhos didático-metodológicos a serem desenvolvidos com os alunos.
\end{abstract}

PALAVRAS-CHAVE: Formação continuada. Saberes docentes. Ensino-aprendizado de matemática. Ensino fundamental.

Academic knowledge concerning the calculation practice in the process of teacher education to teach math

\begin{abstract}
This work was continued in the training course of elementary school teachers "Mídias nas Aulas de Matemática" (Media in Mathematics Classes). The calculation ancient culture is taking early part of the time when man begins to relate objects and join the millions and millions of years. In this article, we know the significance and meanings of calculus from the origin to the present times; understand the different instruments calculate that allows the student to learn the basic operations of mathematics; potentiate the culture knowledge of calculation produced collectively by teachers from municipal, private school teachers, researchers and scholars. During the research, we realized that not only being in favor of or against the use of a calculator or other calculation techniques, we must first know what it is calculator demystifying common sense how to use it, and from there, define the didactic-methodological paths to be developed with students.

KEYWORDS: Continuing education. Teaching knowledge. Teaching and learning of mathematics. Elementary school.

\footnotetext{
Doutor em Educação pela Universidade Estadual de Campinas, professor associado na Faculdade de Matemática da Universidade Federal de Uberlândia (arlindo@ufu.br).

${ }^{2}$ Mestranda em Educação pela Universidade Federal de Uberlândia (balduino.grazielle@gmail.com).

${ }_{3}^{3}$ Doutora em Educação pela Universidade Estadual de Campinas, professora associada na Faculdade de Educação da Universidade Federal de Uberlândia (myrtesufu@gmail.com). 


\section{INTRODUÇÃO}

Os saberes docentes podem ser vistos como um conjunto de ações culturalmente vividas, produzidas e ressignificadas ao longo do tempo. O professor precisa acompanhar as mudanças globais, regionais e municipais de sua comunidade para que a mediação professor-aluno aconteça contextualizadamente. Sabemos que essa atualização do conhecimento não acontece de forma gratuita. É preciso investimento por parte das autoridades governamentais no espaço da escola, na formação continuada de professores e na valorização da mão-de-obra dos profissionais da educação.

A formação continuada dos professores é um investimento importante para a educação. A ressignificação do conhecimento precisa estar em comunhão com o ensino e a aprendizagem dos alunos nas escolas. O curso "Mídias nas Aulas de Matemática" - promovido pela Pró-Reitoria de Extensão, Cultura e Assuntos Estudantis (PROEX), em parceria com a Faculdade de Matemática (FAMAT) da Universidade Federal de Uberlândia (UFU) e financiado pela Fundação de Amparo à Pesquisa do Estado de Minas Gerais (FAPEMIG) - teve duração de dois anos e objetivou a ressignificação dos saberes dos professores.

Dividido em quatro edições, sendo a última voltada para professores do $1^{\circ}$ ao $4^{\circ}$ ano do Ensino Fundamental, o curso teve como metas a formação continuada e o desenvolvimento coletivo de atividades que envolvem a Matemática em um ambiente de construção de saberes e não de reprodução e oralidade e foi desenvolvido para que os professores pudessem ressignificar seus conhecimentos, utilizando as novas Tecnologias de Informação e Comunicação (TICs) como principais instrumentos mediadores.

Desenvolver um curso de formação de professores usando as TIC's (Tecnologias de Informação e Comunicação) foi ir ao encontro das necessidades da comunidade educacional, que ainda permanece na geração do quadro negro e da reprodução do saber em muitas instituições de ensino. As questões que se colocam, hoje, com as informações em tempo real, a lousa digital, a internet, a interatividade dos softwares e equipamentos audiovisuais, são: Como é possível aproximar as novas tecnologias das atividades desenvolvidas com os alunos na sala de aula? Como abordar o tema cultura do cálculo dispondo de aplicativos de última geração?

O processo de reflexão e de produção do conhecimento são algumas das diferenciações mais importantes entre um profissional preparado e um não preparado para mediar o ensino e a aprendizagem dos alunos. Esse profissional necessita da tomada de consciência da realidade para pensar e refletir acerca das possibilidades de utilização das mídias em seu ambiente de trabalho.

Sobre essa reflexão do conhecimento, Alarcão (1996, p. 175) afirma que

a noção de professor reflexivo baseia-se na consciência da capacidade de pensamento e reflexão que caracteriza o ser humano como criativo e não como mero reprodutor de ideias e práticas que lhe são exteriores.

No presente artigo, buscamos compreender a trajetória de constituição coletiva de saberes 
docentes relacionadas à cultura do cálculo e à utilização das TIC's no processo de ensinar e aprender Matemática; analisar os cenários de investigação produzidos pelos cursistas durante o desenvolvimento dos módulos presenciais e semipresenciais; entender a importância da formação continuada e a reestruturação das práticas dos professores; e abranger os conhecimentos sobre a cultura do cálculo e seus desdobramentos na sociedade constituem os objetivos principais deste trabalho.

O processo de realização do trabalho docente em meio a um ambiente cada vez mais virtual e rápido é uma tendência mundial. O desafio é encontrar formas de fazer com que estas tendências cheguem à escola. Os dados coletados foram, em grande parte, produzidos durante os módulos presenciais em conjunto com os professores cursistas, os coordenadores, os pesquisadores e tutores do projeto. A ferramenta virtual mais usada foi o blog, que é um espaço virtual de aprendizagem que melhor se adaptou à cultura digital dos professores cursistas. Esta aceitação por parte dos professores cursistas foi possível com o blog, uma vez que há uma grande facilidade de manipulação das ferramentas, links e postagens, assim como o acesso simplificado. Assim, a coleta de dados pelo blog foi bem significativa para o projeto. Além de todos os benefícios já ressaltados, o blog é também um espaço de interação mediada e de interatividade.

Entendemos que os recursos tecnológicos são importantes para a produção de dados e também na análise, mas não podemos deixar de expor a importância do olhar do observador. Observar é atentar e apreender os acontecimentos, não apenas com os olhos, mas com todos os sentidos do corpo. O pesquisador deve estar atento às mudanças, colocações, gesticulações corporais, interações presenciais e, também, à interatividade.

Neste sentido, o olhar do observador na produção dos dados é de grande importância para a elaboração das notas de campo. Bogdan e Biklen (1994, p. 24) colocam que notas de campo "são os relatos escritos daquilo que o investigador ouve, vê, experiencia e pensa no decurso da coleta de dados". Portanto, no trabalho foram usadas notas de campo, produzidas pelos tutores e bolsistas do projeto.

\section{Tecnologias da Informação e Comunicação nas aulas de Matemática}

O uso das Tecnologias da Informação e Comunicação no processo de ensinar e aprender Matemática requer um entendimento mais amplo, no sentido de nos preocuparmos em saber o que são as TICs ${ }^{4}$ e o que trazem de importante para o espaço da escola. Manipular as tecnologias na escola é diferente da manipulação em outros ambientes. É preciso investimento em tecnologias nas escolas e, também, investimentos na formação contínua dos professores que serão os mediadores dessa tecnologia e do conhecimento em sala de aula. Conforme Ponte (2000, p. 2),

[...] estas tecnologias constituem tanto um meio fundamental de acesso à informação (Internet, bases de dados) como um instrumento de transformação da informação e de produção de nova informação (seja ela expressa através de texto, imagem, som, dados, modelos matemáticos ou documentos multimédia e hipermédia). Mas as TIC

\footnotetext{
${ }^{4}$ A terminologia TIC surgiu inicialmente do computador. Após a criação das impressoras, plotters e scanners, começou a se falar em Novas Tecnologias da Informação (NTI). Com a evolução das telecomunicações, a NTI passou a ser TIC - Tecnologias de Informação e Comunicação. 
constituem ainda um meio de comunicação a distância e uma ferramenta para o trabalho colaborativo (permitindo o envio de mensagens, documentos, vídeos e software entre quaisquer dois pontos do globo).

Ponte (2000) ainda relata, com maestria, que as TIC's são instrumentos de transformação da informação, ou seja, o ser humano produz o conhecimento e utiliza as TIC's para também produzir e ressignificar esse saber. As tecnologias possibilitam criar novas formas de interação e interatividade entre as pessoas, possibilitando os diálogos, as trocas de conhecimentos e informações. Tornam-se uma forma de trabalho essencial no mundo e na escola.

As TIC's, no ambiente escolar, são elementos constituintes no âmbito da aprendizagem. A informação, em conjunto com as tecnologias, faz com que a realidade global esteja próxima à realidade dos alunos. A tecnologia mais utilizada nas aulas pelos professores de Matemática ainda é o quadro negro e o giz. Embora o acesso às novas tecnologias possa ser melhor, se comparada há alguns anos antes, poucos professores e escolas se arriscam nessas novas ferramentas e utilizam outros instrumentos tecnológicos no ensino e aprendizagem de Matemática.

Sabe-se que as TIC são instrumentos importantes na educação e, em especial, na Educação Matemática, uma vez que permitem que uma grande parte dos conteúdos se apóie em softwares educacionais. Além disso, possibilita a criação de um ambiente interativo e facilita a troca de informações, de conhecimentos, a ressignificação do ensino e da aprendizagem. Entretanto, é necessário que os alunos, os professores, a escola e toda a comunidade tenham acesso às tecnologias para, assim, usufruírem de todos os benefícios que os novos recursos tecnológicos podem oferecer.

No curso "Mídias nas Aulas de Matemática", as TIC's foram as ferramentas mais utilizadas pelos professores cursistas, coordenadores, pesquisadores e tutores do projeto. No curso, a principal articulação era buscar integração dessas ferramentas com o ensino e a aprendizagem dos diversos temas do currículo de Matemática. A importância de inseri-las na formação continuada de professores está diretamente ligada às relações de poder, ou seja, saber usar as novas tecnologias é dominar um conhecimento que muitos professores ainda não têm.

O computador foi a ferramenta mais utilizada no curso, devido à sua ampla aplicabilidade na Matemática. Cabe, aqui, a discussão acerca das formas de uso do computador, definidas por Papert (1994) como sendo instrucionista ou construcionista. O instrucionismo está inserido no pensamento tradicional do ensino, há muitas décadas, e ainda é visto como um hábito no trabalho do professor. O autor aponta que, na perspectiva instrucionista, o computador está diretamente ligado ao modo tradicional de ensino, que é a transmissão da informação e a instrução do aluno.

Segundo Papert (1994), é muito comum encontrarmos em nossas escolas professores que tentam repassar a informação aos alunos, esperando que estes se apropriem de tal informação por meio de um processo de "osmose", ou seja, como se o cérebro fosse uma caixa vazia ou uma folha em branco que acomodasse as informações gradativamente. Com esse tipo de metodologia, é difícil uma reação contrária por parte dos alunos. O ensinar e o aprender não são simples, envolvem muitas ferramentas, pessoas, investimentos, a sociedade, as políticas públicas.

\footnotetext{
${ }^{5}$ Osmose é a passagem do solvente de uma solução já diluída para outra com maior concentração, por meio de uma membrana semipermeável. Em Extensão, Uberlândia, v. 12, n. 1, p. 24-41, jan. / jun. 2013. 
Neste sentido, os módulos do curso foram construídos inspirados no construcionismo de Papert(1994):

O construcionismo é uma filosofia de uma família de filosofias educacionais [...]. A atitude construcionista no ensino, não é, em absoluto, dispensável por ser minimalista - a meta é ensinar de forma a produzir a maior aprendizagem a partir do mínimo de ensino [...]. O construcionismo é gerado sobre a suposição de que as crianças farão melhor descobrimento "pescando" por si mesmo o conhecimento específico de que precisam (PAPERT, 1994, p.124-125, grifos no original).

A abordagem construcionista tem como objetivo a construção do conhecimento e compreende o computador como uma ferramenta propulsora desse processo. Segundo Valente (1999, p. 141), “o termo construcionismo significa a construção de conhecimento baseada na realização concreta de uma ação que produz um produto palpável (um artigo, um projeto, um objeto) de interesse a quem produz".

No início do projeto "Mídias nas Aulas de Matemática", foram elaboradas atividades de Matemática sobre números e operações, de modo que estivessem de acordo com a realidade cultural e social dos professores cursistas. Outro ponto importante foi buscar relacionar essa realidade com os softwares gratuitos, as aulas investigativas, os materiais educativos digitais, jogos educativos, objetos de aprendizagem, ambiente virtual e outros para a aplicação no ambiente escolar. Entretanto, durante o curso, foi diagnosticada a pouca vivência dos professores cursistas com as novas tecnologias, isto é, a abordagem desse tema era pouco compatível com a cultura digital dos professores, com o saberes docentes e a realidade da escola.

Ao percebermos uma falta de sintonia no curso, partimos para o desenvolvimento de atividades cotidianas e práticas, com as quais os professores pudessem aprender as técnicas do manuseio do computador, de softwares e homepages, além de elaborarem atividades aplicáveis aos contextos de suas respectivas salas de aula. Os professores, elaborando constantemente suas próprias práticas e desenvolvendo seus saberes docentes, foram estratégias que deram certo e que, até hoje, geram efeitos positivos, segundo relatos dos próprios professores que ainda mantém contato com os coordenadores do curso e bolsistas.

Buscou-se, durante todo o curso, fomentar discussões acerca do papel do professor como produtor e ressignificador do conhecimento, isto é, o professor como sujeito, pesquisador e autônomo. Essa autonomia vai além da sala de aula. Há uma busca pelo conhecimento e não uma estagnação do mesmo. Tonus (2007, p. 39) descreve bem o que seria essa autonomia do professor:

Trata-se da autonomia que transcende a sala de aula, ou seja, permite alterações na ementa, no componente curricular e na metodologia de formação. Essa autonomia permite que eu seja professora-pesquisadora, o que justifica o emprego da metodologia da pesquisa-ação e não de outra mais engessada.

Nesta busca pela autonomia docente, uma pergunta se estabeleceu: qual o papel das TIC's na formação dessa autonomia do conhecimento? Buscando respostas na autora supracitada, encontramos o termo "infotelecomunicação" citado por Denis de Morais (2001 apud Tonus, 2007), que significa o resultado das aplicações das tecnologias. Para Tonus (2007, p. 67), 
as TIC's vêm servindo como meios de transmissão de dados, promotora da interatividade entre docentes e discentes com os computadores, softwares e outros facilitadores do ensino e da aprendizagem e, ao mesmo tempo, veículos de comunicação e interação social.

O professor sempre poderá aprender mais, buscar informações e, ao final desse processo, terá um conhecimento diferente ou uma ressignificação do mesmo, modificando o seu estado inicial. O docente constrói o seu saber na prática educativa e fora dela; está em modificação constante e é urgente que esse professor esteja envolvido na busca pelo conhecimento, na interatividade com outros nichos além do seu, reaprendendo, ressignificando.

Na figura abaixo, percebemos na "Zona Proximal" todos os tipos de interatividades para o desenvolvimento do conhecimento potencial. É de extrema importância destacar que esse conceito foi desenvolvido por Lev Semyonovitch Vigotski (1896-1934) para explicar o desenvolvimento da aprendizagem humana.

Essa ZPD (Zona Potencial de Desenvolvimento) foi significativa para os docentes cursistas e também para coordenadores do curso, pesquisadores e bolsistas, pois nas discussões várias ideias constituíram-se, dando origem a diversos segmentos de pesquisa.

Figura 1: Construção do conhecimento por meio da interatividade e da interação, considerando os ciclos de ações, a espiral de aprendizagem e a ZPD.

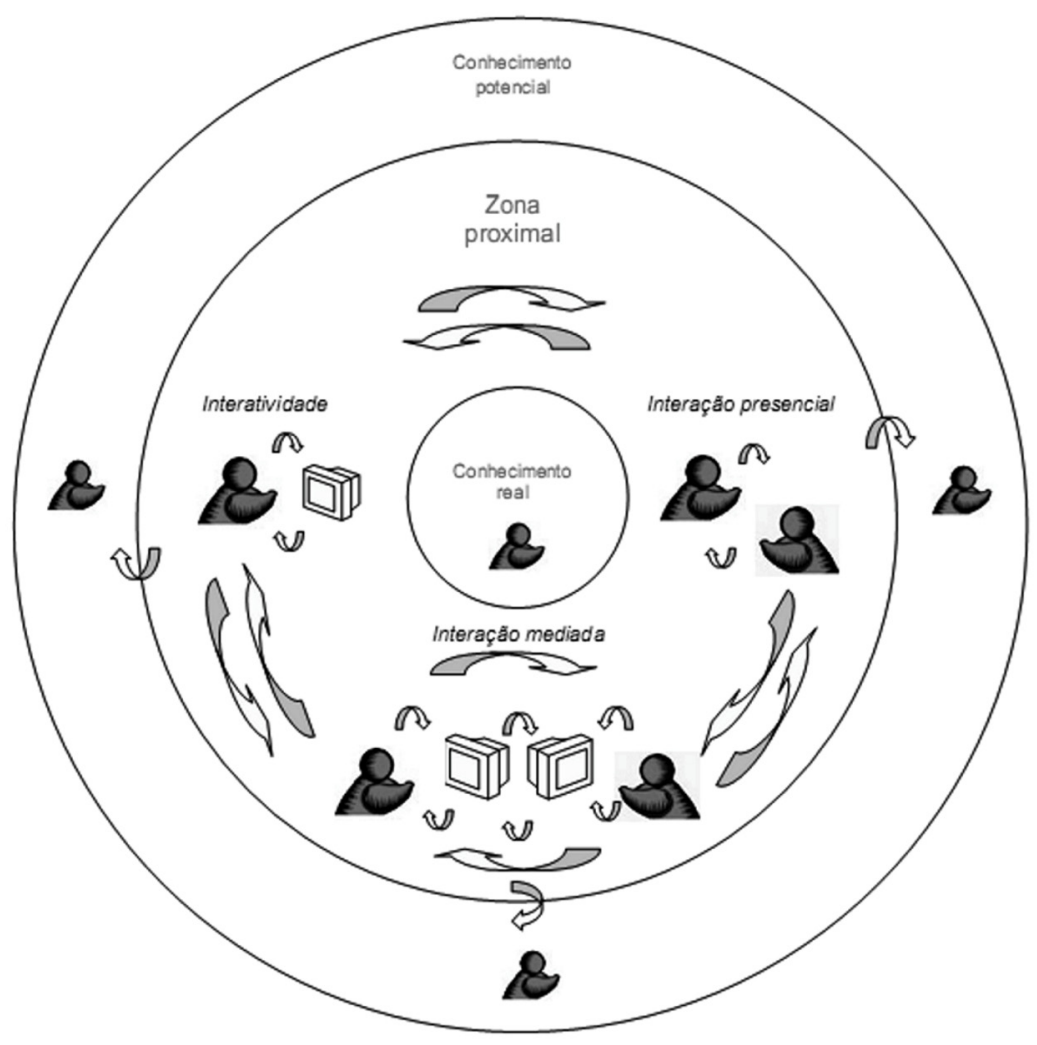

Fonte: TONUS, 2007, p. 82. 


\section{Eixo I: Do diálogo surgem ideias, das ideias surgem diferentes propostas}

A construção de conhecimento coletivo é um dos pontos principais nos encontros com os professores. No curso "Mídias nas Aulas de Matemática", os problemas centrais foram o desenvolvimento da produção e da socialização dos saberes docentes relacionados à utilização do computador no processo de ensinar e aprender Matemática.

Na discussão do módulo, cujo tema era "Material Didático Digital", uma professora expôs o problema do uso da calculadora: "Meu aluno sabe mexer na calculadora, mas eu não posso deixálo usar, pois corro o risco de empobrecer a necessidade do conhecimento com relação à tabuada" (Depoente A). Outra educadora comenta que esclarece aos seus alunos sobre o uso das tecnologias durante cálculos de expressões matemática e completa dizendo: "não basta apenas usar a calculadora, é necessário saber o conteúdo. Ao aplicar um teste, permiti o uso da calculadora, [...], mas sou contra ao uso indiscriminado" (Depoente B).

Este módulo desencadeou um debate com os professores cursistas sobre o uso da calculadora em diversas áreas da Matemática, inclusive para o ensino intuitivo de limite nos cursos de cálculo na sala de aula. A partir dessa discussão, surgiram várias questões sobre o emprego da calculadora na escola: Sabemos realmente as potencialidades da calculadora no ensino e na aprendizagem da Matemática? Quais os significados e sentidos que a palavra "calculadora" pode evocar? Por que em muitas escolas não é permitido o uso da calculadora? Quais as origens dessa ferramenta tecnológica?

A calculadora, desde sua invenção, foi estruturada para agilizar os cálculos, economizar tempo e obter resultados mais precisos. O homem, desde muito tempo, quando ainda vivia em tribos, iniciou a concepção de número e, em seguida, desenvolveu técnicas de cálculos. Com o passar dos anos, houve um aumento natural da espécie em termos de quantidade e de cognição, o que promoveu um crescimento dos mercados internos e, consequentemente, da economia local, mas que só foi possível graças ao aperfeiçoamento das técnicas de cálculos mentais e instrumentais. Oliveira $(1999$, p. 32) aponta que "a presença desses instrumentos em nosso meio fez com que o homem buscasse caminhos para liberar sua mente das operações de rotina e abrisse espaços para sua utilização nos processos que necessitavam de criatividade".

O cálculo sempre foi uma atividade necessária e fundamental para todas as civilizações. Desde 2500 a.C. já havia registros de objetos mecânicos que adiantavam as operações. Um exemplo é o ábaco, um instrumento utilizado por vários povos (chineses, indianos, gregos) na busca por se calcular maiores quantidades em um espaço de tempo, com pouca possibilidade de erro. Na II Guerra Mundial, os cálculos foram indispensáveis nos confrontos. Sobre a história da manipulação dos cálculos, Ponte (1992, p. 12) relata que:

Ao longo da história podemos identificar diversos instrumentos de cálculo que foram sendo utilizados, de acordo com a sua finalidade. Durante a alta idade média, quando os cálculos se realizavam de forma morosa e difícil, era valorizada a capacidade de calcular mentalmente. Nesta época, o ábaco 
era o instrumento de cálculo privilegiado na Europa. Foi apenas no séc. XII que, com a generalização do sistema de numeração decimal que começou a ser substituído progressivamente pelos algoritmos escritos de transporte.

O computador foi pensado a partir de uma máquina tabuladora de dados de cartões perfurados, que calculava a quantidade de respostas dos itens das fichas. A ideia foi do americano Herman Hollerith (1860-1929), que precisou inventar uma forma de totalizar um censo feito nos Estados Unidos, assim o computador surgiu da ideia de se efetuar uma grande quantidade de cálculos em pouco tempo, o que é exatamente o sentido mais restrito da calculadora. A diferença de um computador para a calculadora é que o primeiro incluiu em seu projeto o armazenamento, processamento e a recuperação de dados, atuando também em tomada de decisões, enquanto o projeto da segunda não incluiu tais capacidades.

Oliveira (1999) discute a não dependência entre o computador e a calculadora, abordando as possibilidades da calculadora e seu surgimento, bem como cita o computador como um instrumento que oferece recursos rápidos e eficientes para realizar cálculos complexos:

Com relação a não dependência entre o computador e a calculadora podemos dizer que a calculadora, além de seu papel instrumental de aprendizagem e recurso de potencialização de aquisição de conhecimento matemático, também foi criada para substituir o cálculo manuscrito, que se apresenta muitas vezes em situações de urgência, ou com números de alta grandeza e, portanto, passível de erro [...]. O computador, por sua vez, entre uma infinidade de formas de utilização, possibilita o estabelecimento de novas relações para a construção do conhecimento e formas de atividade mental diferenciadas, oferecendo recursos rápidos e eficientes para realizar cálculos complexos, transformar dados, consultar, armazenar e transcrever informações, o que permite maior tempo para o usuário se dedicar a atividades de interpretação e elaboração de conclusões (OLIVEIRA, 1999, p. 12).

O computador, apesar de serum instrumento intricado, dinâmico e complexo com relação à calculadora, adveio dela. E, por assim ser, pode desenvolver instrumentos de cálculo cada vez mais complexos.

A intenção aqui não é a discussão sobre usar ou não a calculadora e o computador na sala de aula, mas refletir sobre o dever do professor de apresentar e criticar a realidade social com os alunos. D’Ambrósio (1990) relata sobre a necessidade da presença das calculadoras e dos computadores no cotidiano das escolas, principalmente das mais carentes, esclarecendo que, dessa forma, os alunos menos favorecidos socioeconomicamente terão acesso a essas ferramentas que já se encontram disponíveis no mercado de trabalho e que, em um futuro muito próximo, estarão presentes em todos os setores produtivos. O autor afirma, ainda, que, se os alunos que pertencem às classes sociais baixas forem privados do conhecimento e da manipulação desses e de outros instrumentos tecnológicos, certamente serão encaminhados em direção ao subemprego.

Retrocedendo um pouco com relação ao pensamento tecnológico da informação e da comunicação, propomos a análise em um sentido mais amplo do que é calculadora. Para isso, tomemos a tabuada 
como ponto inicial. Usada nas escolas - estampada no lápis ou feita de papel, em forma de cartilhas, nos livros didáticos ou em outros materiais - a tabuada, no sentido etimológico da palavra, é uma tábua de cálculo, seja de multiplicação, adição, subtração, divisão ou qualquer outra operação. A mais culturalmente usada é a tabua de multiplicação.

Existem várias maneiras de se trabalhar a multiplicação sem, necessariamente, decorar a tabuada. O software é um exemplo de que a tabuada pode ser utilizada para motivar o ensino e o aprendizado dos cálculos. O jogo pode ser um veículo motivador na busca por conhecimento. Um exemplo é o software proprietário "Tabuada", que é comprado e licenciado. Esse programa traz diversos jogos de cálculos, sendo um deles o "Batalha Naval", que consiste em posicionar os navios e clicar no valor correspondente a cada quadradinho que o jogador quer atingir, ganhando aquele que conseguir afundar primeiro os navios. Percebemos o quanto é simples esse instrumento de cálculo: desperta emoções por meio do audiovisual e fomenta a vontade de ganhar. Não é um exercício de decorar, uma vez que o jogo cria situações que levam os alunos à concretização do aprendizado.

Sabemos que é complexo o significado do número para as crianças e, até mesmo, para os adultos, por exigir uma reflexão e uma distinção entre número e numeral. Para ajudar nesse sentido, é indicado o jogo "Quantos" do software proprietário Tabuada, que se baseia em uma pergunta no início do jogo: “Quantas unidades a figura ao lado apresenta?”. O jogador, então, conta quantas unidades contém a figura e digita o número na calculadora, que está ao lado da tela principal. A relação biunívoca entre quantidade e número fica explícita, sendo um exemplo interessante para ser aplicado nas séries iniciais.

Nos dois exemplos apresentados, a imagem da calculadora esteva presente em dois sentidos: a imagem convencional do aparelho e as operações que o software desenvolve no decorrer do jogo. A partir daí, é possível perceber os sentidos e significados da calculadora nos dois jogos? São iguais ou diferentes?

Outro exemplo para trabalhar a tabuada, usando a imagem da calculadora, é o jogo Broken Calculator, que é gratuito e facilmente encontrado na internet. A situação apresentada pelo jogo é a "queda das teclas" de uma calculadora que era "normal". A meta é conseguir os números $6,7,8,10,12,15,20,50$ usando apenas os dígitos 2 e 3 junto às operações de multiplicação e soma em um tempo de quatro minutos. O grau de complexidade do jogo aumenta a cada nível, variando do nível 1 (o exemplo apresentado acima) ao 6.

O olhar de vários profissionais da educação sobre a calculadora como apenas um aparelho produtor de contas rápidas e exatas pode mudar. A calculadora (enquanto instrumento com uma tela e as teclas) não se resume a isto, mas, sim, a tudo o que podemos usar para fazer cálculos e produzir resultados, além de poder ser utilizada como objeto de ensino e aprendizagem de Matemática. Qualquer um dos exemplos já citados pode ser um objeto de aprendizagem, por constituir maneiras de formular contas. No Broken Calculator, ficam claras as integrações entre o computador e a calculadora, uma realidade presente no universo tecnológico. Observamos que poucos professores do curso utilizavam a calculadora com os alunos, o que é preocupante, pois agora já é também urgente a presença das novas tecnologias. Nesse aspecto, D’Ambrósio (1986, p. 12) contribui afirmando que:

A ignorância dos novos enfoques à cognição tem um reflexo perverso 
nas práticas pedagógicas, que se recusam, possivelmente em razão dessa ignorância, a aceitar tecnologia. O caso mais danoso é a resistência ao uso da calculadora. Os computadores e a internet são igualmente ignorados nos currículos de Matemática.

Percebemos essa resistência dos professores às novas tecnologias nas discussões nos módulos do curso "Mídias nas Aulas de Matemática". As argumentações dos educadores podem ser analisadas, em sua maioria, como desinformação, falta de qualificação e repulsa ao uso do computadore, principalmente, da calculadora. O desafio foi constante para a equipe que, a cada encontro com os professores, contornava essas situações para que a falta de embasamento científico não estivesse tão presente.

O cálculo mental é, também, muito discutido nas escolas e cobrado dos alunos pelos professores. Outro modelo de aplicativo que desenvolve o cálculo mental de forma interativa é o jogo Cálculo Mental. A ideia é de uma calculadora ao contrário, ou seja, em vez de calcular o resultado, o jogador deverá montar a operação que represente um número proposto por ele. As operações utilizadas são as fundamentais. Esse jogo é uma forma de desenvolver a manipulação das contas em qualquer lugar que haja internet, dispensando o uso do papel, lápis ou outros materiais. É importante notar que o jogo não é uma tábua pronta. O jogador precisa encontrar a expressão matemática que caracterize o número fornecido e, ao fim desse processo, podemos comparar com uma tabuada. Disso, surge o pensamento de que a tabuada é uma calculadora "pronta", isto é, os cálculos e resultados já estão prontos.

Assim, entendendo a tabuada como qualquer instrumento que manipula cálculos e resultados, ampliase o conceito de calculadora. É passível pensar a calculadora degustando outros sabores o sentido. A cultura do cálculo é milenar, embora seus sentidos e significados sejam reestruturados à medida que as necessidades surgem; os homens evoluem; e os sistemas social, econômico, político modificam-se.

\section{Calculadora: sentido restrito e amplo da palavra}

Se perguntarmos para professores, acadêmicos e pesquisadores onde se encontra a calculadora nos softwares aqui apresentados, provavelmente eles apontariam para a figura "mecânica" da calculadora. Há um estereótipo da palavra, que impossibilita qualquer outra interpretação que possa ser feita a respeito. Na tentativa de entender a respeito desse estereótipo, aplicamos dois questionários aos professores do curso "Mídias nas Aulas de Matemática". O objetivo consistiu em saber a dicotomia da calculadora entre professores das séries iniciais. Posteriormente, pretendemos produzir dados relacionados aos alunos e professores de universidades.

A primeira pergunta do questionário foi sobre o posicionamento do professor em relação ao uso do computador. Duas opções foram apresentadas, sendo a primeira "totalmente contra o uso do computador" e, a segunda, "favorável”. Era preciso indicar a partir de qual momento escolar o computador deveria ser utilizado. Dos nove professores que participaram, todos foram a favor do uso do computador a partir da educação infantil. 
Na segunda pergunta, com relação ao uso da calculadora, foram apresentadas duas opções da primeira pergunta. Era necessário indicar a partir de qual momento escolar a calculadora deveria ser aplicada. Dos nove professores, cinco marcaram a partir da educação infantil e quatro a partir da quinta série.

Ora, permitir o uso do computados a partir da educação infantil, sendo este uma calculadora e não permitir o uso da calculadora (aparelho) é uma contradição. Jogos e brincadeiras que envolvem a manipulações de contas e resultados são uma calculadora ou aplicativos? Para responder a essa pergunta, é preciso que se responda o que é calculadora para você?

Conversando com outros autores sobre a calculadora no sentido micro, literal, ou seja, somente enquanto máquina de cálculo, Kilpatrick e Swafford (2005, p. 14) esclarecem que os professores americanos "também estão usando a calculadora, apesar de se preocuparem com a imagem negativa que ela tem [...] em geral, acredita-se que recorrendo a esse equipamento, o aluno não está raciocinando". Ressaltam que "é importante que a calculadora faça parte do material escolar. Se um educador é bem formado em Matemática, deixa que a garotada recorra a ela. Neste caso, o equipamento precisa ser aceito também nas provas" (KILPATRICK; SWAFFORD, 2005, p.14). A respeito da utilização da calculadora no nosso país, os autores esclarecem:

Ouvi que no Brasil isso não é permitido, o que não faz sentido. Quando este recurso é empregado de maneira inteligente, o aluno se torna capaz de questionar, estimar e ser cético. Ele pensa: "Posso ter apertado o botão errado. Essa resposta é razoável? Isso exige uma boa noção dos números e de como o cálculo é feito. A calculadora não é eficaz se a garotada não tiver desenvolvido essa capacidade" (KILPATRICK; SWAFFORD, 2005, p. 28).

Leite (2002, p. 4), ao discutir o papel das calculadoras e o papel dos computadores na Educação Matemática, apresenta a seguinte reflexão: "O uso de calculadoras nas escolas, estranhamente, nunca foi recomendado como é recomendado o uso dos computadores". O autor coloca, ainda, os seguintes questionamentos:

O que os computadores têm a oferecer à Educação Matemática que uma calculadora científica programável e com a capacidade de plotar gráficos não tenha? Comparando a diferença de custos de um computador e o de uma calculadora científica das mais sofisticadas, numa análise de custo-benefício, qual delas se sairia melhor? Em termos de Educação Matemática, qual destas duas ferramentas exigiria um treinamento mais demorado tanto dos professores como dos estudantes? Qual destas ferramentas tem uma porcentagem de rejeição maior quando analisadas ora do ponto de vista dos professores, ora do ponto de vista dos estudantes? Qual destas ferramentas exigiria uma adaptação metodológica mais ampla (ou menos ampla) para permitir o seu uso eficientemente na sala de aula e de forma adequada aos objetivos pedagógicos? (LEITE, 2002, p. 5).

A concepção dos autores acima está ligada à máquina de calcular e não a todo e qualquer instrumento canalizador de cálculo. O computador adveio do cálculo e é uma "calculadora moderna", se pensarmos na grande quantidade de processamento de dados produzidos pelo mesmo. O computador 
e calculadora, com relação ao sentido, entrelaçam-se onde o primeiro derivou do segundo.

No processo de argumentação sobre essas questões, o professor coordenador do curso comentou a fala da professora que havia dito que os pais e a própria escola são contra o uso da calculadora na sala, apresentou o seguinte questionamento:

A calculadora ninguém deixa, mas o computador os pais querem que seja utilizado no processo de ensinar e aprender Matemática; mas como fica agora à utilização da calculadora que está dentro do computador? Os pais são contra ou a favor o uso dessa calculadora?

Este diálogo coletivo provocou um processo reflexivo em todos envolvidos nesse processo. $\mathrm{O}$ coordenador do curso complementa:

[...] cada professor tem um "saber" e que é diferente. Tem aqueles que não têm o "saber" e por isso não conseguem dialogar com os pais e a escola sobre a importância do uso da calculadora e agora com a presença do computador esta questão se tornou ainda mais complexa.

Muitas vezes, os profissionais da educação têm receio de utilizar a calculadora por considerarem que esse instrumento desvirtua os alunos do cálculo mental ou, então, por medo dos pais e/ou da escola. É preciso que haja um diálogo, do professor com a escola e com os pais dos alunos, em torno dos benefícios que a utilização da calculadora pode trazer. É importante o esclarecimento aos pais, que muitas vezes depreendem pouco dos diferentes sentidos e significados que podem ter a calculadora. Cabe à escola, aos pais e aos professores tentar esclarecer o que é calculadora, desempenhando um papel de sujeitos pesquisadores em busca de atividades a fim de compor o ensino e a aprendizagem da Matemática.

O computador possibilita novas relações na construção do conhecimento e diferentes formas de atividades mentais, oferecendo recursos rápidos, complexos e dinâmicos. Cada instrumento tem suas características particulares e nenhum é melhor que o outro. O importante é a integração e a conexão dos diferentes recursos no desenvolvimento do ensino e da aprendizagem de cálculo na educação.

Borrões (1998) aborda o tema “computador” na Educação Matemática e, também, a questão da utilização da calculadora. $\mathrm{O}$ autor coloca que as calculadoras devem estar sempre acessíveis a todos os alunos e que, cada vez mais, os computadores precisam ser utilizados nas escolas. Ele explica que:

Os cálculos longos e complicados devem ser feitos com calculadoras e computadores. O conhecimento da tabuada é fundamental e o cálculo mental é uma capacidade importante. Aprendendo a utilizar o cálculo, os alunos devem desenvolver competências em selecionar o método apropriado: cálculo mental, algoritmo com papel e lápis ou calculadora (BORRÕES, 1998, p. 17).

Borrões (1998) esclarece ainda que, além de instrumento de cálculo, a calculadora poderá ser usada como instrumento de experimentação e pesquisa, permitindo rapidamente testar hipóteses 
e encontrar contraexemplos. Ele defende que a aprendizagem da Matemática deve partir, sempre que possível, de situações-problema e que as calculadoras e os computadores sejam utilizados em ambos os casos. Para o autor: "as calculadoras e computadores devem ser usados de formas imaginativas para explorar, descobrir, e desenvolver conceitos matemáticos e não somente para verificar resultados ou realizar exercícios práticos" (BORRÕES, 1998, p. 21, grifos nossos).

O conceito literal da palavra "calculadora" é o que mais podemos encontrar em diferentes autores, juntamente com a opinião favorável do uso desse instrumento e do computador de forma integrada, desenvolvendo juntos atividades e conceitos. As possibilidades de integração da calculadora com o computador, adicionadas às novas concepções sobre os efeitos que a calculadora pode produzir nas séries iniciais, foi palco de discussões e argumentações do curso "Mídias nas Aulas de Matemática" e será de outras pesquisas que se desenvolverão a partir desse artigo, pois esse olhar ainda não foi totalmente deslumbrado e aceito.

\section{O cálculo e as mídias: refletindo coletivamente sobre o processo de interação de professores num ambiente virtual de aprendizagem}

No curso "Mídias nas Aulas de Matemática", a partir das discussões acerca do uso da calculadora nas aulas de Matemática, foi proposto, pelos bolsistas, um blog, o qual foi bem aceito pelos professores cursistas. Os weblogs ou blogs surgiram no final da década de 1990 e difundiram-se rapidamente devido à facilidade de produção, não exigindo grandes conhecimentos na linguagem HTML.

O blog pode ser usado diariamente e é visto como um diário virtual eletrônico, sendo possível acrescentar links, imagens e vídeos, além de possibilitar a interatividade entre os autores e visitantes. Isso ocorre porque, em cada postagem ou artigo colocado, é possível fazer comentários, havendo, assim, uma interação e uma construção coletiva de saberes em um ambiente virtual.

Nesse sentido, pensamos em utilizar o diário virtual na comunicação, informação e interação entre os cursistas, professores coordenadores do curso, pesquisadores e bolsistas. A ideia do blog surgiu no sentido de viabilizar as discussões sobre a calculadora. O blog é aberto, ou seja, pode ser acessado por qualquer pessoa em qualquer lugar. Sua página inicial é composta por três postagens que ficam no centro. Na lateral direita, há vários links de jogos sobre as operações fundamentais, usando a calculadora. É importante lembrar que esse blog foi desenvolvido para auxiliar na formação continuada de professores das séries iniciais do ensino de Matemática. A ferramenta buscou disponibilizar atividades, jogos, links e discutir com os professores sobre a manipulação da calculadora na sala de aula.

No blog, várias discussões foram propostas, uma delas foi: "Existem vários materiais manipuláveis que trabalham o cálculo. Escrevam quais conhecem e como são utilizados nas aulas”. Uma professora cursista relatou que utilizou os seguintes instrumentos:

Ábaco, material dourado, palitinhos coloridos para cálculos de soma de números inteiros. Uma professora do ensino básico me emprestou o 
material dourado dela, para eu trabalhar com o $6^{\circ}$ ano reforçando e fixando o conceito de adição e subtração com os palitinhos coloridos, vermelhos e azuis, eu trabalho com adição de números inteiros: um palito azul e um palito vermelho se anulam. Outro material para números inteiros é a régua numerada feita com uma folha sulfite e uma janelinha feita também com papel, que, conforme eu movimento, vai me dando o resultado de adições de números inteiros (Depoente $\mathrm{C}$ ).

A professora acima, imbuída na pergunta potencial, descreveu várias maneiras de trabalhar o cálculo com diversos materiais. Essa professora pôde explicitar seus saberes docentes, sendo que, durante as discussões orais do tema "Calculadora e a integração das mídias", realizado em um dos módulos oferecidos pelo curso "Mídias nas Aulas de Matemática", não o fez. O espaço online tornou-se praticável e útil na argumentação dos docentes e ainda foi um ambiente que concentrou links de jogos educativos importantes.

A cultura do cálculo está em todas as direções do nosso cotidiano. Ao acordar, olhamos para o relógio e calculamos, por estimativas, o tempo necessário do café da manhã e para chegar ao trabalho, à escola e a outros lugares. Quando vamos ao supermercado, fazemos estimativas de preços e quantidades; relacionamos preço com quantidade e qualidade para, em seguida, negociarmos a compra. É importante que se perceba a Matemática do cotidiano, não apenas fora da escola, mas dentro dela. O currículo de Matemática na maioria das escolas públicas, pouco se preocupa em contextualizar a Matemática com a cultura socioeconômica, isto é, fazer com que a distância entre a os conteúdos de Matemática e a realidade sejam menores.

Nos Parâmetros Curriculares Nacionais (PCN) são abordadas ideias que não se traduzem na escola. É fato que a Matemática foi produzida e ainda está sendo desenvolvida pelo homem, mas por que não é colocada e estruturada de maneira mais próxima da realidade social da comunidade escolar? Hoje, com as novas tecnologias, os alunos por si só, tem mais oportunidades de aprender sobre vários assuntos, até mesmo o conhecimento matemático. É preciso que a escola, junto com os professores, possibilite diferentes ambientes de aprendizado e ensino próximo da realidade da comunidade e não ignore os saberes dos alunos, mas aproveite seus conhecimentos para propulsar saberes coletivos na sala de aula.

\section{Cálculo e Tecnologias de Informação e Comunicação}

O cálculo está em todas as formas, atitudes e expressões humanas. Surgiu da necessidade do homem, sendo orquestrado e desenvolvido pelo mesmo. Na escola, professores utilizam várias atividades e brincadeiras das quatro operações fundamentais: adição, subtração, multiplicação e divisão, cujo objetivo é fazer crescer o aprendizado e a motivação para os cálculos matemáticos. As crianças aprendem técnicas de cálculo que vão ser úteis por toda a vida. São técnicas criadas e aprimoradas há milhões e milhões de anos.

Uma das características fundamentais antes da arte de calcular é a contagem; a correspondência um a um e a cardinalidade dos números para compreendermos, por abstração, a quantidade de objetos de um todo. $O$ cálculo foi também outra manifestação racional do homem; é uma arte que fornece 
as bases para todo o conhecimento. O cálculo, os saberes matemáticos independente de cor, raça ou religião, todos utilizam, mesmo sem perceber, as teias de cálculos que são formadas no subconsciente.

No cotidiano, quando precisamos calcular o preço de uma mercadoria, o tempo gasto para o deslocamento de uma região a outra, os gastos financeiros de um estabelecimento ou até mesmo da residência, recorremos, muitas das vezes, à calculadora. É confortável obter os resultados de um cálculo de forma ágil e eficiente sem precisar fazer contas usando apenas a mente e/ou o lápis e papel. As tecnologias digitais foram desenvolvidas para trazer uma maior comodidade, praticidade e aperfeiçoar o conhecimento em muitos aspectos. Mas o que as escolas utilizam como base para o desenvolvimento do cálculo? Calculadora, computadores, brincadeiras, cálculo mental, material dourado ou todos juntos?

Sabemos que são muitos os desafios para os professores na busca da aprendizagem e do ensino dos alunos, principalmente em relação às quatro operações fundamentais. Segundo Vergnaud (1996, p. 45), "um dos grandes problemas do ensino é desenvolver ao mesmo tempo a forma operatória do conhecimento, isto é, o saber-fazer, e a forma predicativa do conhecimento, isto é, explicitar os objetos e suas propriedades". Em outras palavras, são objetivos aparentemente simples, mas que, na prática, passam por grandes impasses que a escola, em conjunto com os professores e a comunidade, precisa discutir e solucionar, a fim de que o aprendizado e o ensino dos alunos possam acontecer de forma plena.

\section{Material Dourado Digital: aprender ou reaprender?}

Na discussão sobre o que é calculadora e o uso desta nas aulas de Matemática, diversos materiais foram citados como sendo objetos "facilitadores" das operações fundamentais (adição, subtração, multiplicação e divisão). Um dos mencionados foi o "material dourado", que, além de ser realmente um objeto potencializador do aprendizado nos anos iniciais do ensino, é utilizado com frequência em várias escolas municipais e instituições particulares.

O material dourado foi descoberto por Maria Montessori, que se inspirou em uma necessidade vital da criança: o aprender fazendo. Cada criança tem um ritmo de desenvolvimento e aprender fazendo é proporcionar uma aprendizagem e um ensino no tempo e no espaço adequado a cada uma. $\mathrm{O}$ material dourado é composto por placas quadriculadas, cada qual contém as seguintes quantidades: placa das centenas, placa das dezenas e as placas unitárias. Normalmente, o material dourado é feito de madeira, mas pode ser encontrado no plástico ou na borracha de EVA(Etil Vinil Acetato).

O material dourado é muito utilizado na fase em que as crianças estão aprendendo o CAVALU (Quadro Valor de Lugar), que surge como um recurso didático que colabora na significação e na contextualização dos conceitos matemáticos como agrupamento e posicionamento dos numerais e na ampliação das possibilidades didáticas em Educação Matemática. Muitas vezes, os alunos têm dificuldades em entender o sistema de posicionamento dos números e reagrupamento. No quadro valor de lugar, há uma interação com o material dourado, no intuito de sistematizar e representar os agrupamentos, sendo que os alunos visualizam as junções e a aplicação direta nos cálculos. 
A versatilidade do material dourado e a sua nova versão nas novas tecnologias digitais fez surgir o "material dourado digital". Com as mesmas características do material dourado concreto, o material dourado online permite uma complementação do material dourado "concreto", uma vez que possibilita a quebra das barras de dez nas operações. Não pretendemos, aqui, indicar qual material é mais adequado nessas atividades - se é o material dourado concreto ou o virtual -, mas, sim, discutir a integração dos objetos na aprendizagem e no ensino de cálculo. Os juízos de valor (os materiais serem bons ou ruins) quanto ao uso dos materiais nas atividades devem ser analisados de acordo com cada aluno, em um determinado ambiente escolar, inserido em uma dada comunidade.

A partir do blog da calculadora, vários outros espaços virtuais foram produzidos com o objetivo maior de interagir, integrar e construir saberes sobre a educação Matemática e o ensino e a aprendizagem do cálculo. Um desses espaços virtuais foi o blog "Mídias e o material dourado", que explorou vários assuntos sobre o material dourado e as mídias num mesmo contexto. Além disso, este blog reuniu várias atividades do material dourado como: bingo, material dourado virtual, tabuada, jogo "nunca 10"; vídeos e jogos online das operações fundamentais. Os objetivos principais do blog foram concentrar diversos materiais, atividades e mídias sobre a cultura do cálculo em um mesmo ambiente, facilitando o acesso dos professores cursistas aos materiais; promover discussões online sobre o uso do material dourado digital e concreto no desenvolvimento do cálculo. O blog foi construído para o curso "Mídias nas Aulas de Matemática - 4ª Edição", que foi desenvolvido no CEMEPE (Centro Municipal de Estudos e Projetos Educacionais Julieta Diniz), na cidade de Uberlândia-MG.

\section{Aplicando ideias e produzindo conhecimentos}

Os professores do curso "Mídias nas Aulas de Matemática", por meio do blog "Mídias e o Material Dourado", observaram o quanto são vastas as possibilidades de atividades que envolvem a manipulação do material dourado, tanto concreto quanto virtual. Nessa perspectiva, como requisito obrigatório para a conclusão do curso, os professores desenvolveram várias atividades utilizando os materiais e os temas fornecidos pelos coordenadores, durante os módulos. O material dourado foi um tema que, além de ter agradado, foi o que mais produziu trabalhos por parte dos professores cursistas nas escolas onde atuavam.

Dentre os trabalhos apresentados pelos professores, destacamos um desenvolvido no laboratório de informática de uma escola municipal para uma turma do Ensino Fundamental que consistiu em utilizar o material dourado virtual. Na aplicação, a professora determinava algumas operações para que os alunos pudessem resolvê-las no software. Segundo ela, a aula foi tão motivante que os alunos se ajudavam, trocavam técnicas de operações e, ao final da aula, nem perceberam que já estava na hora de voltar para a sala de aula. "Foi fantástica a aplicação desse material", disse a professora mentora da atividade ao final apresentação da proposta para os outros professores cursistas.

O material dourado digital, segundo o relato dos professores que aplicaram efetivamente o software, é também uma mídia que leva à investigação e compreensão dos conceitos de operações na base decimal, produzindo resultados significativos com turmas do PAV (Programa de Avaliação 
da Vida Escolar) e turmas regulares do ensino fundamental.

\section{CONSIDERAÇÕES FINAIS}

Pesquisar sobre o cálculo e suas diferentes diretrizes implicou em vivificar momentos de descobertas e discussões significativamente construtivas no processo de formação continuada de professores que ensinam e aprendem Matemática. No trabalho desenvolvido, restaram mais incertezas que soluções, pois acreditamos que o cálculo é historicamente produzido de acordo com seu tempo e sua gente. A cada geração, novas técnicas são apresentadas e descobertas, ressignificando as maneiras de se pensar e aprender a operar os números e produzir cálculos.

Falar em cultura do cálculo, muitas vezes, exige abertura de novas técnicas e ferramentas que auxiliem no desenrolar das manipulações das operações, embora essa ideia não seja sempre comum entre os professores, a escola e os pais dos alunos. É necessária uma conscientização entre todos os envolvidos no processo de ensinar-aprender sobre a importância das novas tecnologias para o ensino do cálculo. Não basta ser a favor ou contra o uso da calculadora, que é uma ferramenta ímpar nas práticas de calcular. É preciso ter argumentos válidos, conhecer as ferramentas tecnológicas e, em conjunto com a realidade dos alunos, criar práticas para sua utilização.

Desenvolver trabalhos para auxiliar professores do ensino básico a aplicar atividades investigativas, interativas e que promovessem a autoria dos alunos foi um desafio, mas, ao final do curso, percebemos que cada professor ressignificou seu saber docente por meio da socialização do conhecimento e da disposição em querer modificar sua prática no ambiente escolar.

[...] os professores produzem diferentes sentidos para o trabalho coletivo e que esses são associados ao seu papel no grupo e à sua história de vida. Ao compreendermos que somos movidos pelas relações sociais e que nossa subjetividade é constituída na qualidade das relações (SOUZA JUNIOR, 2003, p. 211).

O curso "Mídias nas Aulas de Matemática" propiciou trocas, ressignificações, produções, discussões e interações sobre diversos temas, contribuindo não só para a formação dos professores do Ensino Fundamental, mas também com a formação de discentes, tutores do curso, pesquisadores e docentes da universidade. Novos sentidos para desenvolver o ensino e a aprendizagem do cálculo, utilizando as novas tecnologias e outros materiais, foram apresentados. O mais importante é que percebermos que estes novos significados e sentidos foram compartilhados entre os professores do Ensino Fundamental e, principalmente, por seus alunos.

\section{REFERÊNCIAS}

ALARCÃO, I. (Org.). Formação reflexiva de professores: estratégias de supervisão. Porto: Porto, Editora, 1996. 
BOGDAN, R. C.; BIKLEN, S. K. Notas de campo. In: Investigação qualitativa em educação: uma introdução à teorias e aos métodos. Porto: Porto Editora, 1994.

BORRÕES, M. L. C. O computador na educação matemática. 1998. Disponível em: < http:// www.apm.pt/apm/borrao/matematica.PDF >. Acesso em: 25 mar. 2009

D’AMBRÓSIO, U. Etnomatemática: arte ou técnica de explicar e conhecer. São Paulo: Ática, 1990.

D’AMBRÓSIO, U. Da realidade à ação: reflexões sobre a Educação Matemática. São Paulo: Summus, 1986.

KILPATRICK, J.; SWAFFORD, J. National Research Council. Helping Children Learn Mathematics. 7. ed. Washington, DC: National Academy Press, 2005.

LEITE, A. S. A Educação, as máquinas de calcular e os computadores. 2002. Disponível em: <http://200.169.53.89/download/CD\%20congressos/2002/2\%20CBComp/html/artigos/ informatica\%20na\%20educacao/ine001.pdf > . Acesso em: 10 abr. 2009.

OLIVEIRA, J. C. G. Catalogação e descrição bibliográfica: a visão dos professores de matemática do Estado do Paraná em relação ao uso de calculadora nas aulas de matemática. 1999. Tese (Doutorado) - Universidade Estadual de Campinas, Campinas, 1999.

PAPERT, Seymour. A máquina das crianças: repensando a escola na era da informática. Tradução de Sandra Costa. Porto Alegre: Artes Médicas, 1994.

PONTE, J. P. As TIC no início da escolaridade: Perspectivas para a formação inicial de professores. 2000. Disponível em: < http://www.educ.fc.ul.pt/docentes/jponte/docs-pt/02Ponte \%20\%28TIC-INAFOP\%29.pdf >. Acesso em: 13 out. 2009.

PONTE, J. P. O computador um instrumento da educação. Porto: Texto, 1992.

SOUZA JUNIOR, A. J. Informática e cultura profissional: o laboratório de informática da escola como espaço de formação. In: FONSECA, S. G. Currículos, Saberes e Culturas Escolares. Campinas: Editora Alínea, 2007.

TONUS, M. Interações Digitais: uma proposta de ensino de radiojornalismo por meio das TIC. 2008. 262f. Tese (Doutorado) - Instituto de Artes /Universidade Estadual de Campinas, Campinas, 2008.

VALENTE. J. A. O computador na sociedade do conhecimento. Campinas: UNICAMP/ NIED, 1999.

VERGNAUD, G. A trama dos campos conceituais na construção dos conhecimentos. Paris: Editora Nathan, 1996.

Submetido em 22 de março de 2012.

Aprovado em 17 de setembro de 2012 